\title{
Albeiro, un "Profeta" colombiano en Camboya
}

\section{Albeiro, a Colombian "Prophet" in Cambodia}

DOI: http://dx.doi.org/10.18566/comunica.n40.a07

Recibido: 13/03/2019 - Aceptado: 29/05/2019

- Kep es la provincia más pequeña de Camboya, de 336 kilómetros cuadrados y una población que no sobrepasa las 41.000 personas. Entre ellas se encuentra Albeiro Rodas, un colombiano con una particular historia de vida, de esas que nos devuelve la esperanza en la humanidad-

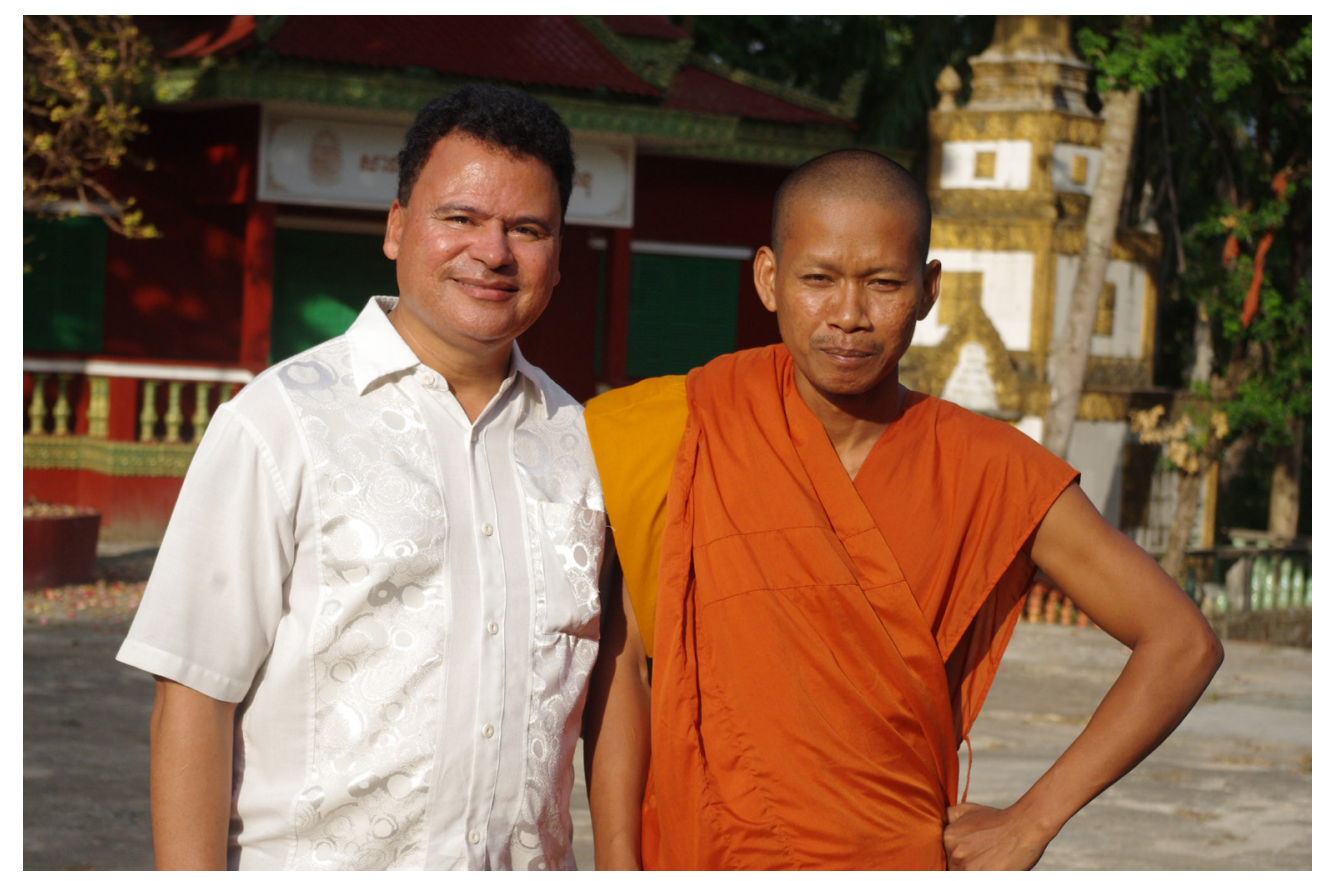

Indochina parecía haber recuperado a ese hijo extraviado que volvió para darle algo de vida a este sitio olvidado por el mundo. Foto: Silvia Córdoba

\section{0}

Comunicación

número 40

Enero-junio

2019 | pp. 90-97

\section{Carlos Andrés Aguirre González}

Comunicador Social-

Periodista, UPB. Free

lance en Sydney-Australia

carandre77@hotmail.com 


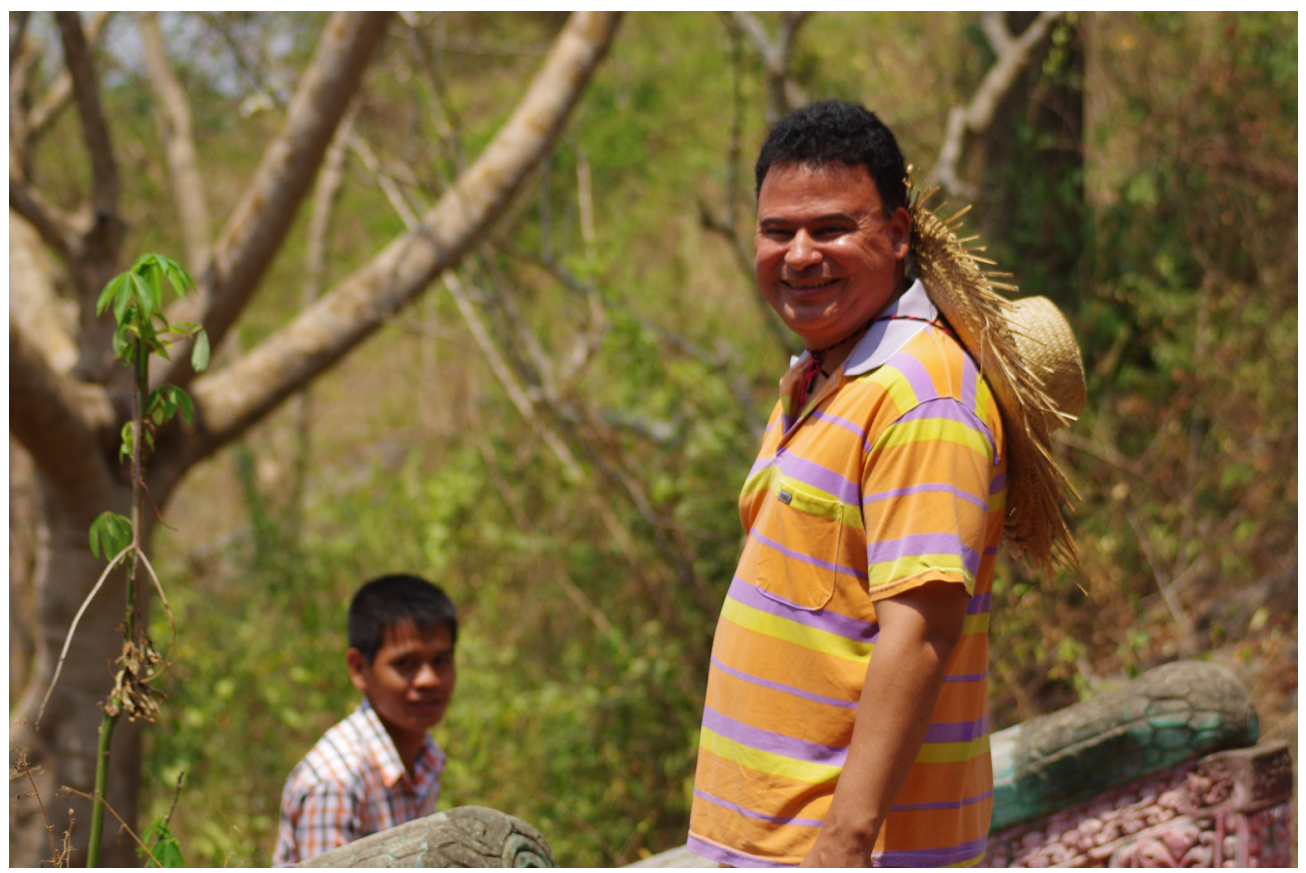

El misionero Rodas nunca ha considerado dejar este indescriptible país asiático, en donde asegura ser feliz viendo a los otros vivir de lo que han aprendido con él y con los suyos. Foto: Silvia Córdoba

Sus mejillas se ensanchan y se cierran los ojos; esos que se vuelven casi una línea, que vibran con su sonrisa, la que parece llevar tatuada en su rostro; a medida que cuenta su prontuario profesional, religioso y humano. Parece que el que nació en el barrio 12 de Octubre de Medellín, Colombia, nunca llevó consigo rasgos latinoamericanos, sino los mismos de esa Indochina; la zona del Sudeste Asiático que parecía haber recuperado, hace más de diez años, a ese hijo extraviado que volvió para darle algo de vida a este sitio olvidado por el mundo; una Camboya donde la población es un 80\% campesina y un dólar es para la mayoría la cuota de supervivencia diaria.

Albeiro, fundó en 2011 un tecnológico llamado Don Bosco Technical School. Acá llegan a diario 250 jóvenes camboyanos entre los 17 y 22 años a recibir clases de comunicación social, agricultura, secretariado, programación, hospitalidad y electricidad; cursos por los cuales deben pagar una cuota de 100 dólares semestrales; aporte que su fundador traduce en "un progreso para ellos, porque recibirlo todo gratis no muestra el verdadero valor de las cosas, no solo materiales, sino la misma educación que debe tener un valor único para quien la recibe". La mayoría de ellos obtienen alimentación y servicio de lavandería, la que lleva por nombre "Lavandería Medellín". 


\section{Todos los Caminos Conducen a Camboya}

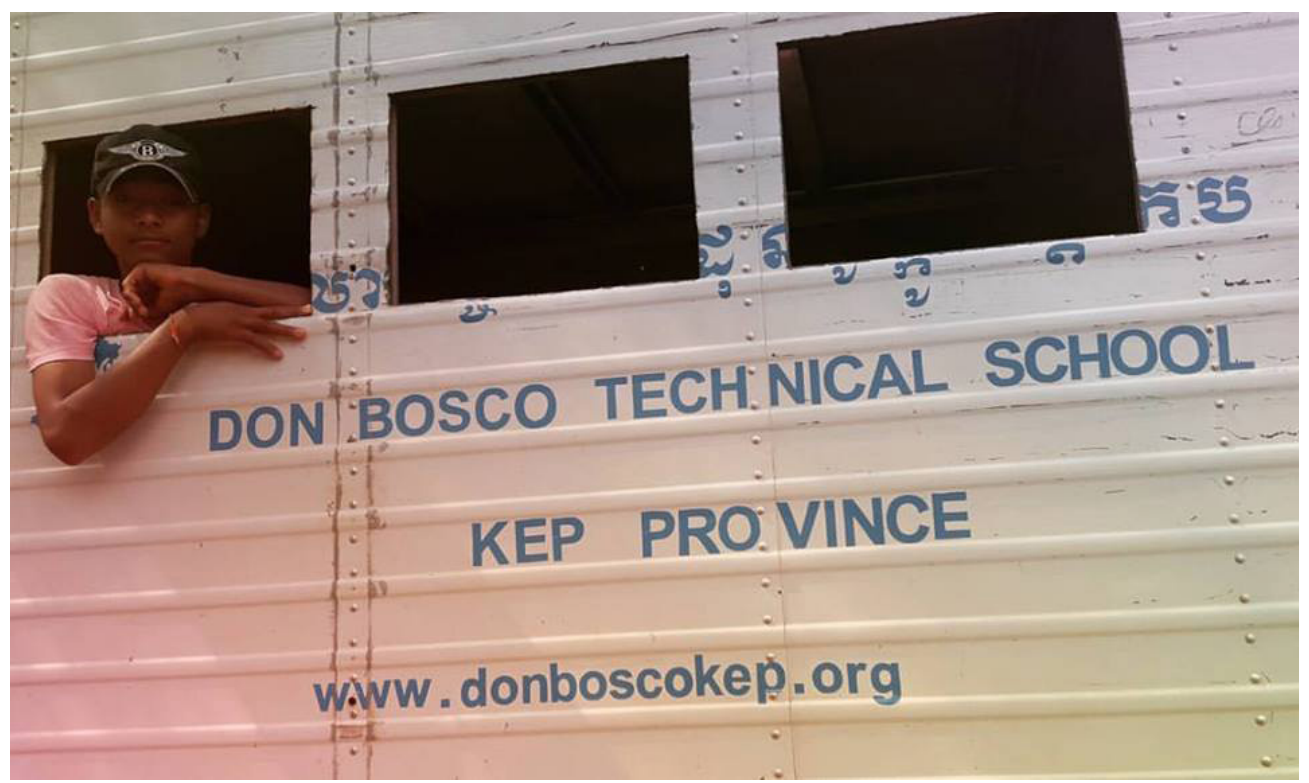

En el año 2013 se realizó la inauguración oficial del tecnológico, la primera institución que enseña en inglés en toda la historia de la Provincia de Kep. Foto: Silvia Córdoba

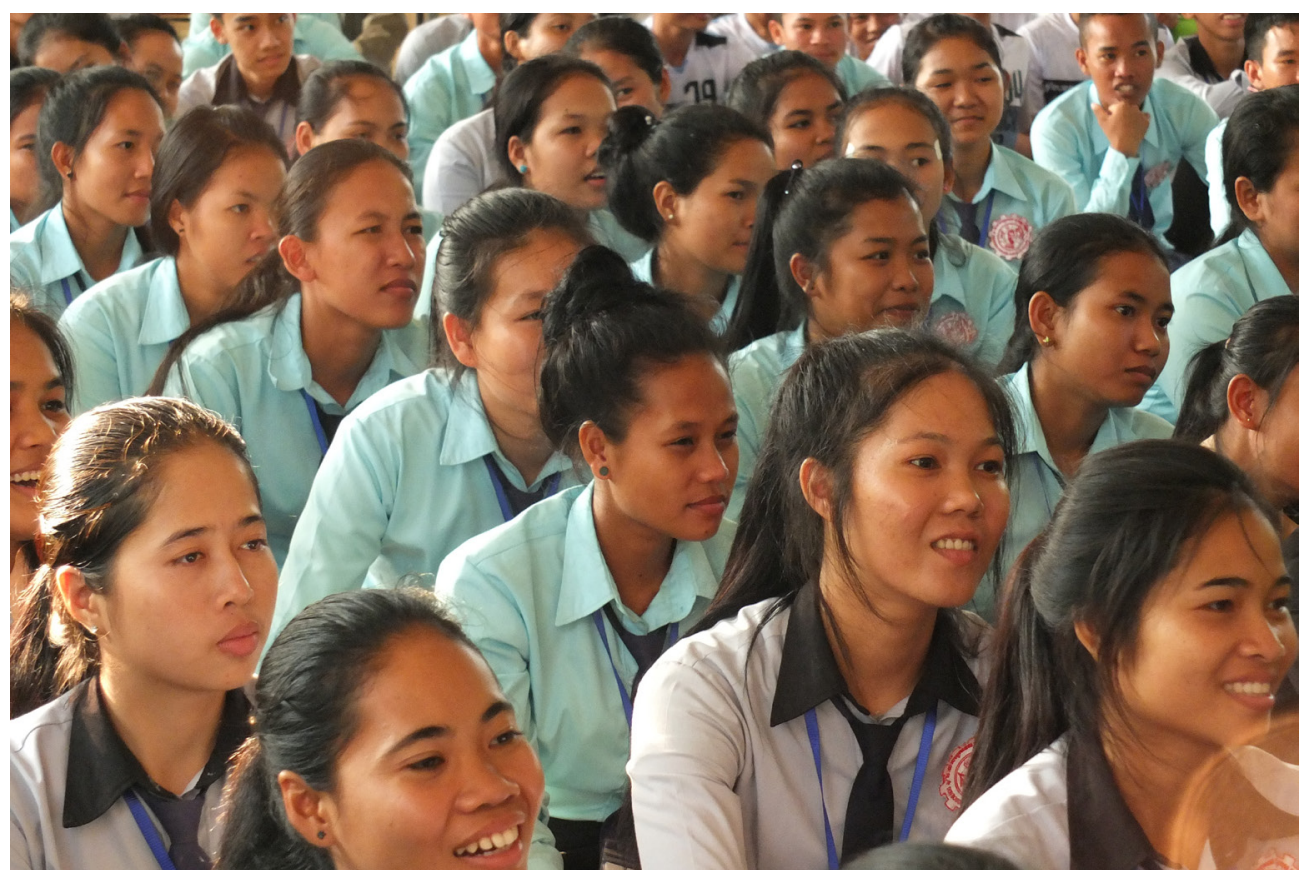

Electricistas ingleses y periodistas colombianos, son algunos de los que han dado meses de cátedra a estudiantes que hablan un inglés muy básico. Foto: Silvia Córdoba 
El siglo pasado ya tenía sus meses contados cuando el comunicador social de la Universidad Pontificia Bolivariana recibía una carta desde Roma, donde se le notificaba que había sido aceptado para empezar su preparación para ser un misionero por el mundo. Ya en la capital italiana, un profesor de la escuela de San Bosco le mostró un mapamundi, donde le señalaba Camboya como un destino donde podría dar un gran paso como misionero; al ver la proximidad de este país con China se sintió más que emocionado, ya que desde niño soñaba con conocer la nación del "Sol Naciente", sin saber que su próximo destino quedaba a 2.592 kilómetros de esa tierra anhelada. En sus recorridos por el mundo estuvo en Filipinas, Israel e Irlanda, allí estudió inglés; ahora es todo un políglota que habla la Khmer, la lengua camboyana, como si fuera un nativo.

El misionero de San Bosco jamás pensó en sus inicios que podría llegar a cambiar la vida de Vuthy, Bonny, Rothá, Bi, Ming, Ly, Sambó y la de los otros miles de jóvenes que han pasado por las aulas de este tecnológico. El que se sostiene con aportes de benefactores franceses, ingleses, alemanes, italianos y estadounidenses; quienes dan el mayor porcentaje para que este proyecto no se derrumbe. "En ocasiones nos toca trabajar con lo que tenemos en el momento. Aquí las personas con discapacidades físicas son marginadas por la sociedad, por eso este año juntamos el dinero para construir rampas y ascensores para ellas, las que hacen parte de nuestros muchachos", cuenta con orgullo Albeiro, mientras mira, con el sol posado en su tez, el pedazo de océano que linda prácticamente con el jardín de su instituto; lugar del que dice no envidiarle nada a ningún club campestre en el mundo.

Un profeta siempre necesitará de sus discípulos para expandir sus profecías. Estos son los voluntarios de todo el globo que llegan cada año, a no solo compartir su conocimiento con los estudiantes, sino también a dejarse envolver por un país que le podría partir la vida en dos a cualquiera. Electricistas ingleses y periodistas colombianos, son algunos de los que han dado meses de cátedra a estudiantes que hablan un inglés muy básico, pero que cada lección la tratan de aplicar en sus prácticas de una manera muy particular y en ocasiones sorprendente para sus maestros. Uno de ellos es la colombiana, magister en comunicación educativa, Silvia Córdoba; según ella, acá ha llegado para desaprender todo lo que durante años ha aprendido, para tener el cerebro de nuevo en blanco y enseñar en un contexto inimaginado. 


\section{Periodismo, una "religión" incluyente}

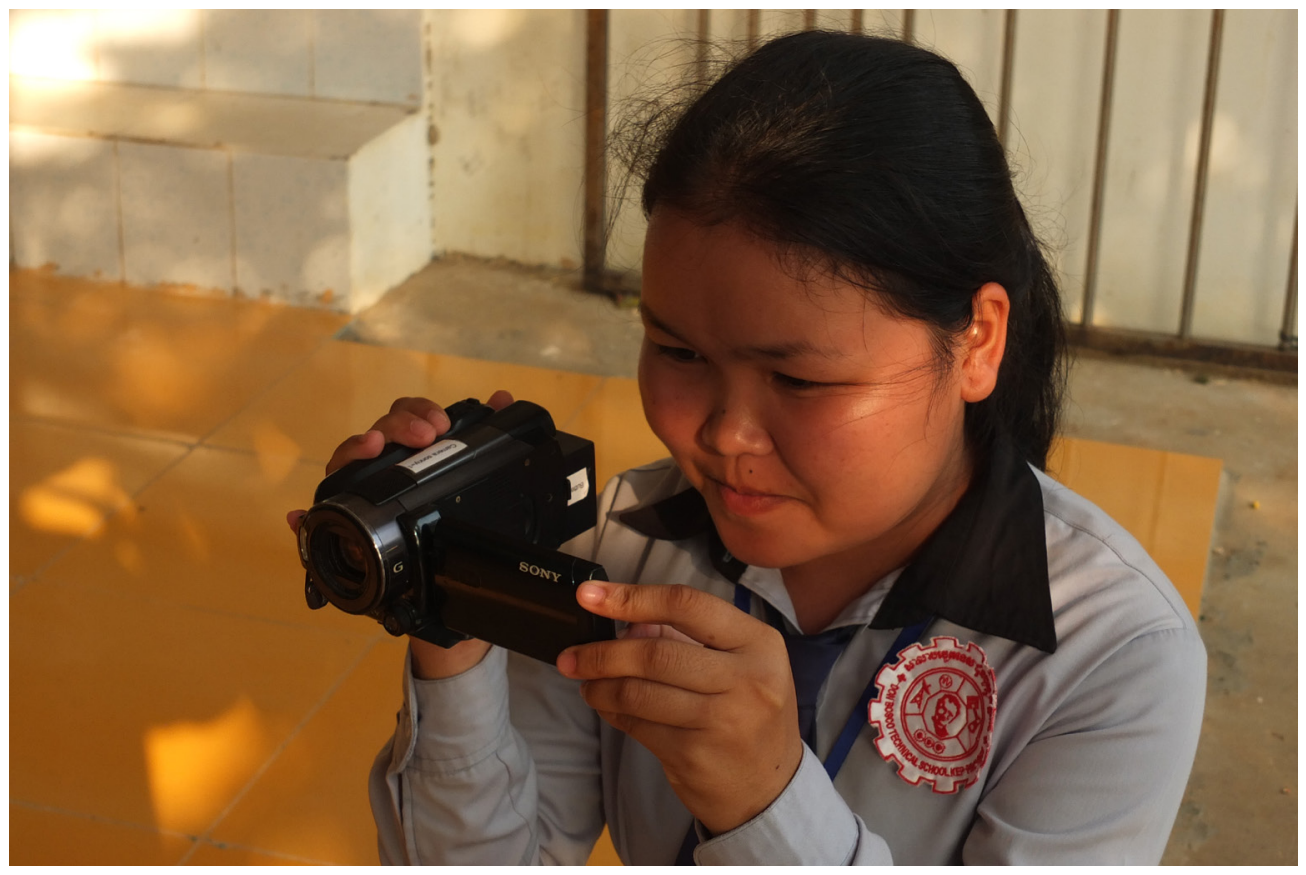

Una de las áreas a las que más le ha dado importancia es la de Comunicación Social y Periodismo. Foto: Silvia Córdoba

En el año 2013 se realizó la inauguración oficial del tecnológico, la primera institución que enseña en inglés en toda la historia de la Provincia de Kep. Para ese día se organizó una ceremonia, en la que muchos esperaban la típica eucaristía católica por las raíces del fundador y sus benefactores. Pero no fue así, Albeiro tomó la vocería e invitó a hacer una oración en cada una de las religiones de los presentes; dejando claro que este no sería un centro de conversión católica como muchos lo podrían ver en un principio. "En un país con un 95\% de adeptos a la religión budista; no hay razones para imponer creencias que las personas no llevan en su día a día. Acá tenemos musulmanes, católicos y hasta animistas; todos en un mismo lugar, no se habla de religión, simplemente de educación, hasta los mismos voluntarios son de diversas creencias religiosas", asegura el director del Instituto.

Una de las áreas a la que más le ha dado importancia es la de Comunicación Social y Periodismo. Perplejos, muchos de los presentes en el salón, que no tiene más de 30 sillas, miran atentos a Silvia, quien intenta explicar los principios de la teoría de la imagen.

“Este año me fui cinco días con los estudiantes de documental a recorrer en moto 14 templos de la época preangkoriana, son templos hinduistas entre 
los siglos IV y VII que nadie conoce y que no están en las guías turísticas. Fuimos a grabarlos e hicimos un registro audiovisual que no se había hecho en este país, y menos por un grupo de camboyanos", cuenta la profesora Silvia, cronista de Universo Centro.

Albeiro ha intentado que varios de sus "discípulos" tengan la misma pasión que él por la carrera de la que se graduó en el año 94, para este hombre es la única religión que se impone dentro de este lugar; una comunicación sin distinciones de personas, ni mucho menos de creencias.

Sin importar las condiciones climáticas, los estudiantes van en sus bicicletas dejando una marca sobre los polvorientos senderos de piedra y ladrillo triturado mientras van camino a sus clases; algunos de ellos tienen que pedalear por más de una hora para poder llegar muy en la mañana al instituto.

Este es un país donde las son risas de sus habitantes se vuelven un símbolo para quienes visitan esta tierra, más rica en gente que en recursos; no hay ningún momento en el que una expresión alegre no te esté siguiendo, pareciese que las personas se levantaran con una sonrisa y la dejaran en sus rostros para poder vivir, o en este caso, sobrevivir.

\section{Una cátedra para el mundo}

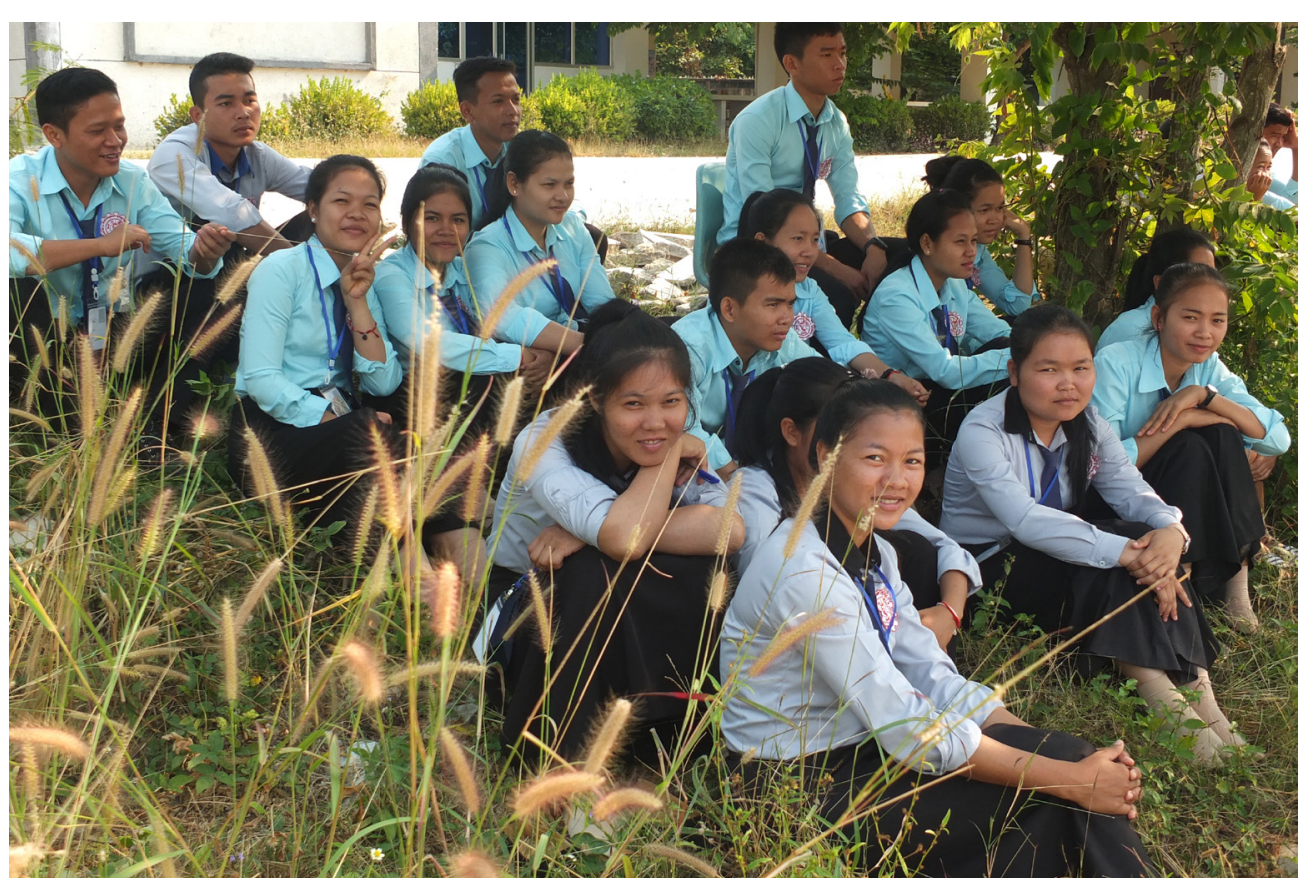




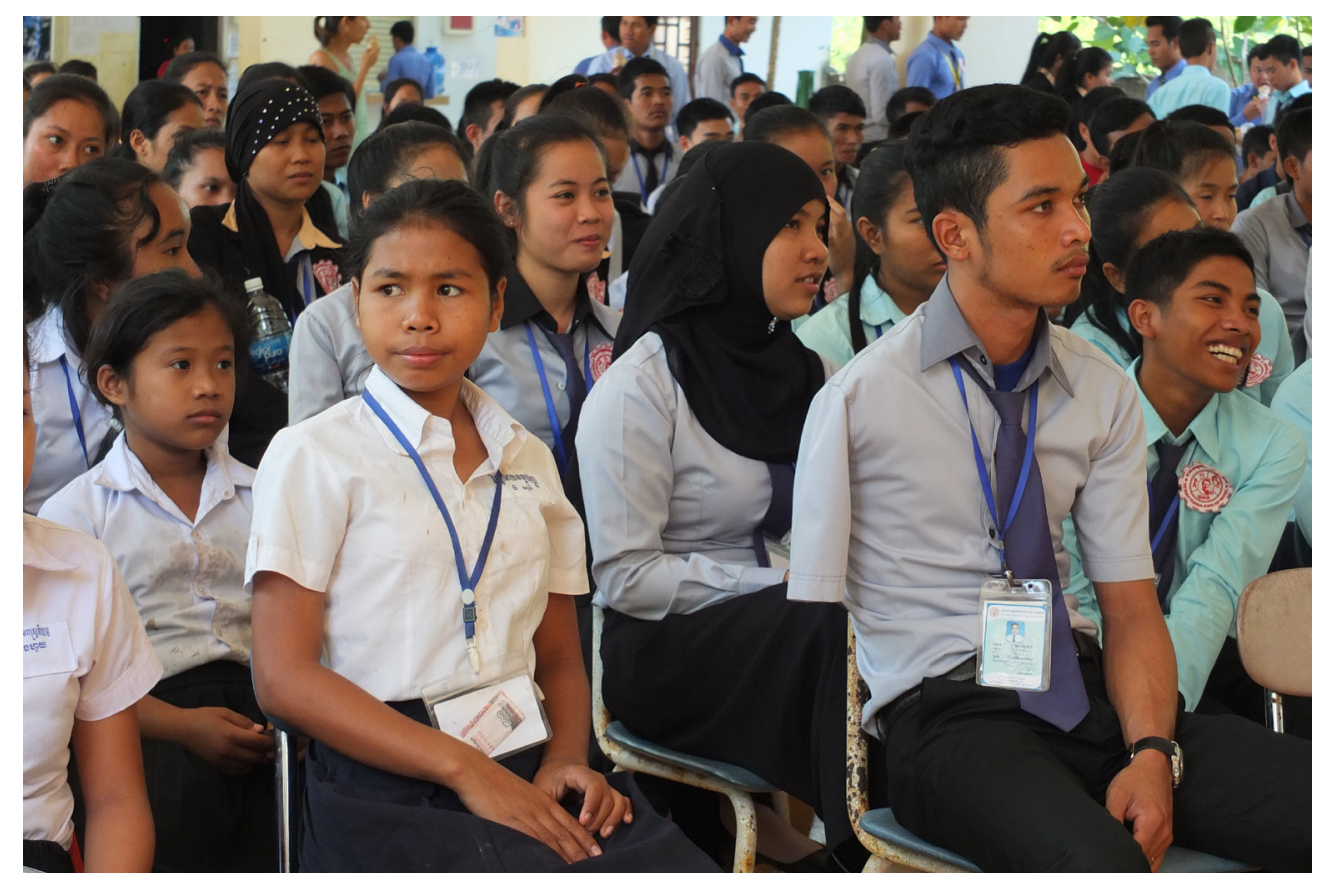

"Acá tenemos musulmanes, católicos y hasta animistas; todos en un mismo lugar, no se habla de religión, simplemente de educación", Albeiro. Foto: Silvia Córdoba.

Muchos desconocen la historia de Camboya, un país que sufrió uno de los más grandes genocidios de la historia, quizá el último que se ha conocido por la humanidad. Este fue obra del régimen de los Jemeres Rojos, liderados por Pol Pot, de ideales del maoísmo y el estalinismo; un hombre que fue capaz de ordenar la muerte de casi un cuarto de la población camboyana, cerca de tres millones de personas murieron entre el año de 1974 y 1979. El líder de este atroz episodio buscaba purificar la población, era como una especie de Hitler sin bigote. Hasta la fecha se han encontrado un poco más de 20.000 fosas comunes, en lugares llamados Campos de la Muerte, donde los árboles aún conservan las marcas de los latigazos a los que eran sometidos los detractores del régimen.

"Ver que después del genocidio todos decidieran ponerle punto final al tema y ahora viven juntos víctimas y victimarios, sin andar pidiendo castigos, esto es lo que muestra un pueblo con una capacidad de resiliencia increíble de la que tenemos mucho que aprender", nos cuenta Silvia Córdoba, quien ha atendido ya en dos ocasiones el llamado de Albeiro para seguir educando a "sus muchachos" camboyanos, como él les llama; y así seguir entregándoles un poco de ese mundo del que quizá la vida, los dioses y hasta el mismo destino los han privado. 
El sol ya da sus últimos bríos en Kep, en un rincón de la provincia se ve el tecnológico San Bosco, donde solo queda Albeiro; quien cierra la puerta de su oficina y comienza a pasearse por las aulas. Allí donde va esa parte de la primera generación camboyana a educarse después de varias décadas, la que por cuestiones de las guerras de otros ha sido relegada a un tercer plano en el mundo. El misionero Rodas nunca ha considerado dejar este indescriptible país asiático, en donde asegura ser feliz viendo a los otros vivir de lo que han aprendido con él y con los suyos. 